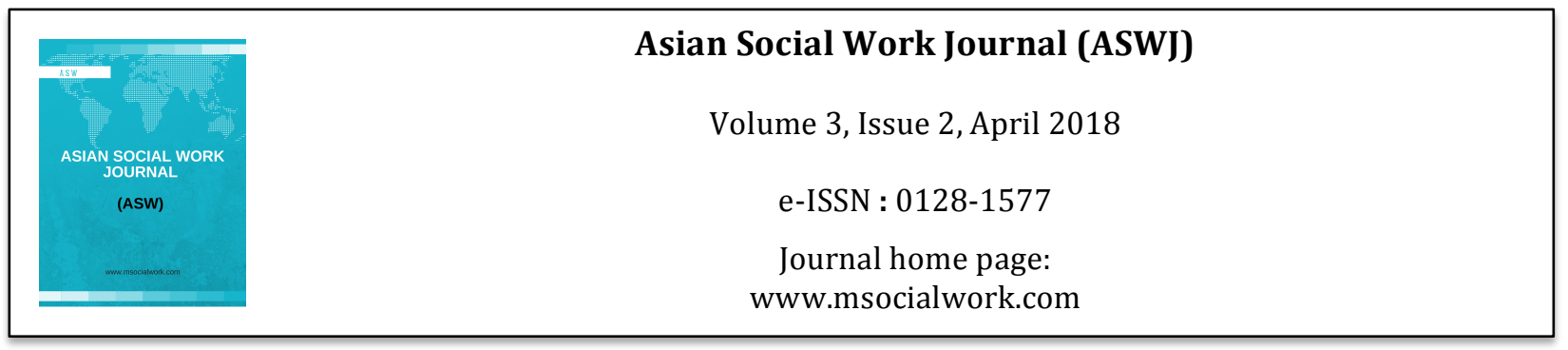

\title{
The Healthy and Hygienic Behavior: Analytical from Social Construction Perspective
}

\author{
Muria Herlina ${ }^{1}$ \\ ${ }^{1}$ Department of Social Welfare, University of Bengkulu, Indonesia \\ Corrrespondence: Muria Herlina (muriaherlina@yahoo.co.id)
}

\begin{abstract}
This research aimed to find out the healthy and hygienic behavior at the Lebong County Bengkulu Province regarding on external and internal environment, objective judgment, baby delivery, breastfeeding, toilet, and the domestic non-smoking prohibition. The qualitative approach was used with subjects of the research were 16 housewives, with purposive sampling method applied, and 15 key informants who hold either formal or non-formal authority in the society. The data were obtained through in-depth interviews, observations and documentations. The results showed that the social reality in terms of baby delivery stemmed both from primary socialization (family: grandmother, mother and mother in law) and secondary socialization (internalization or education) that had become a tradition from one generation to the next generation. Another interesting fact is that a great number of mothers do not breastfeed their baby. Instead, they started to give supplements food to their 3-and-4month old babies, such as water and honey, water and sugar, or rice porridge with coconut sugar. The community also seemed to be unfamiliar with the concept of healthy toilet as they fulfill the call of Mother Nature in random places, such as in the river, behind the trees, or in the sewer. Furthermore, it is not an easy task to have a non-smoking prohibition in every single family since smoking has become an externalized habit and a symbol of masculinity. The researcher concluded that the healthy and hygienic behavior was heavily influenced by a stock of knowledge derived either from the primary source (family) or from the secondary source (significant influence from key figures or education). Other factors that also had a great influence upon the implementation of the healthy and hygienic behavior in the society were poverty, distance and location, healthy facilities, and communal habits.
\end{abstract}

Key words: social-constructive, behavior, baby delivery, breastfeeding, toilet, smoking

\section{Introduction}

Sanitary and healthy life style (SHLs) is one form of health sector developments in Indonesia. It is programmed in the form of health promotion, "Healthy Indonesia 2010". National Vision of Health Promotion defined as SHLs 2010, scheduled to achieve the Millennium Development Goals (MDGs) by 2015 , it also aims to achieve the Indonesian people who live in a healthy environment, healthy behaviors, affords to reach fair and equitable health services and achieve high quality of health. There are 10 indicators of SHLs in the family structure ${ }^{1-2}$, namely: (1) giving births attended by health professionals, (2) exclusive breastfeeding, (3) Scaling the baby and toddler every month, (4) Using clean water, (5) Using healthy latrine, (6) having houses that are free from mosquito larvae, (7) Washing hands with soap and clean water, (8) Eating fruit and vegetable every day, (9) doing physical activity every day, and (10) no smoking in the house. 
This research based on the failure phenomenon of "Healthy Indonesia 2010". The failure can be seen from the low achievement SHLs in Indonesia, because the average achievement rate of 10 indicators PHBs is still low ${ }^{3}$, such as: (1) Giving births attended by health professionals is $64 \%$ while the national target is $90 \%$, (2) Exclusive breastfeeding 39, 5\% while the national target of $80 \%$, (3) Only $35 \%$ of mothers who scale their babies and Toddlers while the national target of $80 \%$, (4) Using clean water $35 \%$ of the national target of $85 \%$, (5), Washing hands with clean water and soap $19 \%$ of the national target of $80 \%$, (6) Using healthy latrines $49 \%$ of the national target of $80 \%$, (7) ) having houses that free from mosquito larvae $35 \%$ of the national target of $80 \%$, (8) Only $16 \%$ eats fruits and vegetables every day of the national target ${ }^{2}$ is $65 \%$, (9) Only $18 \%$ of people who perform physical activities of the national target of $65 \%$, and (10) Only $36 \%$ of Indonesian population who do not smoke in the house while the national target is $65 \%$. If the percentage of the number ten performance indicators combined such SHLs target, the average reached $34.65 \%$ is still far from the average national target of $77 \%$. Because of the wide scope of the SHLs, this study only examines four indicators of giving birth, exclusive breastfeeding, using healthy latrines, and no smoking in the house. The reason is because it is relevant to the HDI (Human Development Index).

The failure of SHLs in giving birth context, exclusive breastfeeding, using of latrines and smoking in the house healthy have impacts on maternal mortality rate (MMR) and infant mortality rate (IMR) and increase lung cancer patients. Being estimated to be around 585,000 maternal deaths each year is caused by complications of pregnancy, childbirth, and chilbed, which could have been prevented, if the childbirth assisted by health personnel ${ }^{4}$. Death in infants $(9 \%)$ and Toddlers $(13 \%)$ is due to diarrheal diseases. In 2009 , there was gone up ${ }^{4}$ to $19.2 \%$ due to dirty environment and unsanitary latrine in general ${ }^{5}$.

The failure could be due to socialization SHLs in developing countries that tend to imitate health development programs in the modern countries. The problems are not all conditions starting from knowledge, educational background, customs, traditions, and conceptions of society. Both in developing and in developed countries are in the same condition, such as how to overcome health problems, patterns of births and deaths always change due to behavioral factors, culture and the environment are not the same in every state ${ }^{6}$.

Criticized against modernization development is largely a political ethics while social changes are taking place today, especially in developing countries around the world, almost all policymakers have similarities in one thing: whether or not, they inevitably focus on the actions in making decisions 'Western-style' without thinking about the situation of their country, because the problems of development in each country are very different ${ }^{7}$. These conditions encourage the writer to have study on the health development and service in developing countries (particularly in Indonesia), because Indonesian government is also criticized, reflected from a variety of evidences that have been described previously.

The percentage of smokers in Indonesia ranks the third in the world ${ }^{3}$ is 65 million smokers or $28 \%$. One of the provinces in Indonesia is Bengkulu province, which occupies the highest number of smokers $^{3}$ among 33 provinces, reaches $29.5 \%$. It means that smokers in Bengkulu province are higher than national is. Lebong regency as one of 10 regencies in Bengkulu province that occupies lower percentage $^{4}$ is $32.7 \%$, but it still far from the national target ${ }^{8}$ at $77 \%$.

The phenomenon above is interesting to be studied deeply, specifically using Berger and Luckman theory of social construction, as a tool to analyze the SHLs problems in this study, because the study of SHLs using the theory of social construction has not yet been done. Through the theory that is interpretive and humanistic, tends to consider individuals who interact as precise analysis instruments, afford to develop how the social world is formed that the reality of everyday life has dimensions of subjective and objective and men are an instrument to create social reality 9 .

Observing the phenomena above, the question formulations will be answered in this study "how are the family members in Lebong district of Bengkulu province construct SHLs according to Berberian perspective?" Based on the formulation of the problems that the purpose of this study is to examine 
Berger and Luckman's social construction theory about the meaning of SHLs in the family toward the reality of life as new findings in discussing health issues related to the human behavior.

\section{Research Methods}

This research is a qualitative study using phenomenological approach which is a research design can evolve and be open according to the real conditions. Adaptation to the real conditions is done to improve the relevance of research problems, theories and concepts, as well as the methods used in accordance with the nature of the humanities, the objective result of the research is not based on evidence, generalizations, but the understanding and meaning as the construction of transferability. This approach is directed to the individual background holisticly (as whole), Berger and Luckman's social construction in externalizing and internalizing process toward the SHLs practices (childbirth, exclusive breastfeeding, healthy latrine and no smoking in the house).

Data collections were done by using in-depth interviews, observation and documentation. Research informants were 31 , it consists 16 housewives is taken by purposive sampling and key informants (formal and informal community leaders) there are 15 have been determined by various considerations and other requirements ${ }^{10}$.

The techniques of data analysis were done by collecting the data, the results of observations, interviews, notes, documentation that collected, informants' activity during the study are reviewed. The data is reduced, ie. choosing the principal things that relates to the theme and needs to focus on the research about 4 indicators for SHLs. Reduced data have provided a sharper picture of the observations and make it easier to answer the research problem. Further research conclusions are drawn.

\section{Research Results}

\section{The childbirth social reality assisted by Health Personnel}

The reality of childbirth in Lebong constructed in 3 types of aid childbirth system, namely (1) being assisted by piawang (traditional childbirth attendants). Piawang's' help has much in demand by families in Lebong, people feell more comfortable because both still have a family relationship, more experience, inexpensive, can massage and expel spirits or the devil (non-medical issues) that often interfere the infants and mothers, and the infant care lasts longer (7-9 days), as well as they feel fear with the medical devices (midwife). (2) being assisted by midwives has professional reasons such as hygiene, using medical equipment, providing vitamins, overall they also think more expensive but safer. In fact, it is chosen by a few pregnant women. (3) choosing a midwife and piawang help will feel safer and more comfortable, pregnant women check their pregnancy with midwives but giving birth with piawang. This way is only a few chosen by families in Lebong. The reality of childbirth constructed by:

Table 1. Description Childbirth Family in Lebong, Bengkulu Indonesia

\begin{tabular}{|c|c|c|}
\hline No. & $\begin{array}{l}\text { Characteristics of } \\
\text { Research Subjects }\end{array}$ & Childbirth Social Construction \\
\hline A & & $\begin{array}{l}\text { Childbirth Description assisted by Piawang (traditional } \\
\text { childbirth attendants) }\end{array}$ \\
\hline 1. & $\begin{array}{l}\text { Housewives have } \\
1-4 \text { children, } \\
\text { elementary to } \\
\text { junior high school } \\
\text { education, } \\
\text { economic class }\end{array}$ & $\begin{array}{l}\text { - Cheaper costs, not to be paid with cash, accept any kind of } \\
\text { payments that will be received by piawang. } \\
\text { - Feel more comfortable, more experience, often help people } \\
\text { give birth, still have family relationships. } \\
\text { - Piawang provides water for babies to take bath that mixed }\end{array}$ \\
\hline
\end{tabular}


can not afford

2. Housewives have 1-2 children had high school education, middle and lower economic classes

3. Informants assess children 2-3 people educated up to high school junior, middle and upper economic conditions

4. Housewives from middle to upper class, junior to senior high school education, cadres some traditional spices, feel fresher. Piawang can repel spirits that often interfere with maternal (could overcome non medical problems)

- Low cost, do not attach rates, adjusted for family conditions, Feel more comfortable, piawang helps the baby to take bath for 6-8 days.

- Feel healthier, piawang provides warm water that has been given some spices to the mothers who had given birth during 3 days. If the body feels tired, piawang can massage.

- Feel comfortable with piawang attended childbirth until delivery. Feel good, massage before and after delivery if the body feels tired.

- Have pleasure, piawang assists the baby to take around to 68 days.

- Feel fresh after taking bath that provided by piawang during 3 days after delivery, feel so fragrance. Piawang has more experience.

- Giving birth with Piawang has less guaranteed for hygiene. cannot afford checking the health condition of the mother and fetus. Could not give vitamins for pregnant women.

- Although inexpensive, can undoubtedly save for mothers and children if there are abnormalities in the delivery process.

Among the descriptions of informants' statement results in Table 1 above, they state that "I've given birth 3 times all helped by piawang because I followed my mother and grandmother. They given birth were always helped by piawang (shaman). Giving birth with piawang was safer because it could drive supernatural creatures. It was low cost and infants cared until their cords were released" (interviewed on July 2013, SWN, Sellers, 32 years old, Junior High School).

Furthermore PPT stated that "though it is cheap, I do not want to give birth with piawang because it is not guaranteed cleanliness, I can not check the health of the mother and baby and she can not give medication if something happens in labor" (Interviewed, June 2013, PPT, household, 27 years old, senior high school).

\begin{tabular}{|c|c|c|}
\hline B & $\begin{array}{l}\text { Characteristic of } \\
\text { Research Subjects }\end{array}$ & $\begin{array}{l}\text { Delivery Description assisted by health professionals } \\
\text { (midwives) }\end{array}$ \\
\hline 1. & $\begin{array}{l}\text { Housewives have } 1- \\
4 \text { children, } \\
\text { elementary to junior } \\
\text { high school } \\
\text { education, } \\
\text { economic class can } \\
\text { not afford }\end{array}$ & $\begin{array}{l}\text { - More expensive, cost from Rp.400.000,- to Rp } 600,000,- \\
\text { - Only accept payment with taci/money (cash). Let patients } \\
\text { stay alone, reason: delivery is still a long time } \\
\text { - Can not expel spirits that often interfere the pregnancy and } \\
\text { during labor can not massage the patients }\end{array}$ \\
\hline 2. & $\begin{array}{l}\text { 1-2 housewife has } \\
\text { educated children } \\
\text { from elementary to } \\
\text { high school, middle } \\
\text { and lower economic } \\
\text { classes }\end{array}$ & $\begin{array}{l}\text { - Costs are relatively expensive, although expensive if having } \\
\text { harm for mothers and fetus try to borrow some money to } \\
\text { other members of the family or relatives for giving birth } \\
\text { and midwives could give some drugs. } \\
\text { - being terrified or fear with medical equipment, such as } \\
\text { install oxygen, infusion, or tension }\end{array}$ \\
\hline
\end{tabular}

3. Informants chose 2- - Giving birth with midwives more hygienic premises. 3 children up to $\quad$ Safer, in case having complication or abnormalities for the 
junior high school educated, middle and upper economic conditions

4. Mother household from middle class to upper, education SLTP up to SLTA, cadres Posyandu. fetus and mothers, could be referred to a doctor.

- Although more expensive, but feel safer because there is medical equipment.

- feel convenient because midwives are more educated and have practiced in the hospital or maternity clinic during their college.

- More professional, more hygienic, more experience to help childbirth address medical problems, have complete equipment, and medicine, knowing when it is pregnant women time to give birth.

- expensive cost does not matter, focus on the mothers and children to have safer and healthier. If there are health complications can cost up to a million or more, because the drug is so expensive.

- it is no problem if inviting a midwife and piawang to help childbirth assistance, if the mother and fetus healthier, tend to choose to give birth with piawang because it is more comfortable, and have family relationships, while the midwive only check the pregnancy, because they feel safer and the midwives have special education (professional).

Delivery assistance realities were helped by health workers informed by informant, namely:

"For my family the security and safety are the most important, even the cost, since I was pregnant I had already saved money. During my pregnancy my midwife checked it. When giving birth, midwives and piawang assisted me. The midwife understood health issues, while piawang could care for the baby longer, she could massage, gave traditional medicine and supplied spices for water that used to take bath, I was also happy using the traditional way" (interviewed, July 2013, ENT, housewife, 20 years, junior high school)

\section{Social Realities of Exclusive Breastfeeding}

Exclusive breastfeeding for the baby is given only breast milk for 6 months are not found in any familes in Lebong, although they know from counseling, watching television or reading magazines. They have reasons that non exclusive breast milk produces in two days after giving birth, when the baby is crying and licking his lips, interpreted by family members that the baby is thirsty or hungry. while waiting out the milk, the baby is fed some honey water, sweet water or tea, drop into the baby's mouth. Infants at the age of 3-4 months are given additional foods such as rice flour porridge mixed with brown sugar (palm sugar), smoothed rice (filtered), boiling rice water (water starch) or Promina porridge. The reasons of early giving supplementary feeding for the infants or non-exclusive breastfeeding are (1) in order the infants feel full longer (2) the infants grow fastly and they are fat but health, (3) Quickly obtain smart or fast growth, and (4) infants often cry despite being breastfeeding, and (5) There is an opinions that infants just give breastfeeding are not enough, they shuold give additional food . in addition to all these reasons. There is a different reality because the mothers' primary purpose does not give exclusive breastfeeding for their infants that the mother may soon be possible to leave the baby at home alone, to help her husband's job in the garden or other works. If the work is done by both will earn more money. The situational conditions means that the level of income (poverty) will impact on exclusive breastfeeding. 
Table 2. Informant characteristics and

Descriptions of Social Construction of Exclusive Breastfeeding

\begin{tabular}{lll}
\hline No. $\begin{array}{l}\text { Characteristics of } \\
\text { Research Subjects }\end{array}$ & $\begin{array}{l}\text { Descriptions of Social Construction of Exclusive } \\
\text { Breastfeeding }\end{array}$ \\
\hline
\end{tabular}

1. Housewives have 1- $\quad$ Not understanding the exclusive breastfeeding, exclusive

4 children, elementary to junior high school education, low economic class breastfeeding means it gives to their babies until 2 years old, having a little breast milk secretion.

- Providing additional complementary foods to their babiess at the age of 3 months.

- when the babies like to feed any additional food is fine as long as the babies like it

- Babies have diarrhea when given extra food is not a serious problem, gradually recover.

- Efforts to expand out the breast milk that traditionally eat cinnamon, young papaya curry, breast smeared with chili leaves is finely grinded and eat young palm leaves.

2. Housewives have 1- $\bullet$ Knowing exclusive breastfeeding from TV and magazines, 2 children who graduated from senior high school, middle and lower economic classes but do not apply it, being busy to help their husbands work in the garden /rice field, so the babies (at the age of 3 months) have been given additional food, the babies can leave alone for a long time, do not depend on breast milk anymore.

- being accustomed from their grandmothers that babies at the age of 3 months or older have been trained to eat rice flour porridge mixed with brown sugar, produce a lot breastmilk, treated by traditional medicine.

3. Informants chose 2- $\quad$ Knowing exclusive breastfeeding from TV, magazines, 3 children who graduated from junior till senior high school, middle and upper economic classes doctors or midwive, knowing mak (mother) and sister or other family members, if the children are quickly given extra food such as rice flour porridge, boiled bananas or other fast food, able to grow fat bodies.

- Feeding the baby is more practical to buy it, like SGM, Promina porridge or others sold in any pharmacies or shops, when making it by themselves is no necessarily guaranteed for hygiene.

- Babies are given extra food (non-exclusive breastfeeding) if there are activities such as work, help husband or invited to the parties, and the babies do not depend on their breastfeeding.

- Producing much breast milk, eating more vegetables or banana blossom.

4. Housewives from

- Breastfeeding discharges much since having pregnant middle to upper class, graduated because of much eating vegetables, drinking milk and fruits, exclusive breastfeeding is more economical, more from junior to senior hygienic high schools,

- Knowing exclusive breastfeeding program from TV news, 
integrated service station cadres (kader posyandu) magazine, doctors and midwives.

- Non-exclusive breastfeeding as mothers follow their parents' advice, babies at the age of 3 months above start to eat solid food in addition to having breast milk, extra food can buy in stores, stalls or pharmacies

- Children with diarrhea and fever given extra food earlier, stopped it firstly. Treated to a midwives or doctors in Muara Aman (downtown of Lebong district). After recovering, try again to eat the food step by step, and when the babies recover and no more diarrhea, the food continues to eat.

"Much breast milk secretion does not usually produce much until 1-3 days, when my first child was born, my milk secretion was little, my grandmother and mother taught to eat vegetable young palm trees and it is true. After eating young palm tress two times, my breastfeeding was lot of discharge" ( Interview , June 2013 . SRN, 40 years, Farmer, Junior )

"All of my three children, when they were 3 months old already trained to eat porridge of rice flour and water mixed sweet sugar. Generally we are in this village (Ketenong I) feeding our babies at the age of 3-4 months. It aims that the babies do not depend on the breast milk, so I can help my husband's work or other chores. I am not worried because this procedure was from generation to generation. Followed my mother or grandmother's old habits, there are no problems on my baby" ( interview, July 2013MSB, housewife, 36 years, SD ).

"Mostly the economic society level in Lebong regency are meddle or lower class, so it is normal that a lot of women who help their husband to work in the fields. Its is hoped that if they both will be higher earned. But it is not only farmers who are not mothers member exclusive breastfeeding her baby, but mothers mothers who work in kantorpun do not give their babies breastfeeding, because of the government regulations on maternity's leave is generally only for one month before and after they give birth, so the mother is hard to do exclusive breastfeeding for their babies" (interviewed, August 2013, AGTN , 35, S2, one of Members of Assembly of Lebong regency).

\section{Realities of the use of Healthy Latrines}

Healthy environment is the goal of SHLs, but the facts are found in this study, only a few families who have healthy latrines. In this condition, majority of the families in Lebong do not have healthy latrines. In general, most of the family members defecate in the rivers, in the siring (gutter) or in the garden behind or beside their houses. Families have wc (healthy toilet) because some reasons are(1) daughters in law come from outside of Lebong district, feel embarrassed if their sons or grandsons unusually defecate in the river, (2) having rich children (prosperous) can provide their parents' houses with wc (toilet). (3) parents feel embarrassed if their childrens' friends are from other districts coming to visit their houses (4) The healthy family behaviors that house should have clean toilet. Unfortunately the criteria in point 4 , it is still very little done by the family in Lebong regency. Some information found on how to use healthy latrine, the details can be seen in table 3 .

Table 3. Informal characteristics and Social Construction Description of Healthy Latrines

\begin{tabular}{lll}
\hline No. $\begin{array}{l}\text { Characteristics of } \\
\text { Research Subjects }\end{array}$ & The Social Construction Description in using Healthy Latrines \\
\hline 1. & $\begin{array}{l}\text { Housewives have 1- } \\
4 \text { children, } \\
\text { elementary to junior } \\
\text { high school } \\
\text { education, low }\end{array}$ & $\begin{array}{l}\text { - Mising is kind of defecation in the river is more practical } \\
\text { - Defecation in the river can interact with their neighbors when } \\
\text { they met at the river }\end{array}$ \\
Defecation in the river has become a habit from generation to \\
generation
\end{tabular}


economic class

2. Housewives have 1-

2 children graduated from senior high school, middle and lower economic classes

3. Informants choose 2-3 children who go to junior or senior high schools, middle and upper economic class

4. Housewives from middle to upper class, junior to senior high scool educations, integrated service station cadres (kader posyandu)
- build a family's latrine or toilet costly

-Want to build latrines / toilets, but their money for more important need such as for food and school fees

- If there are their children's guests from outside, parents are ashamed not to have latrines, but how they are not able to build WC

- There is a wc or toilet in the family built by the sons, daughters and grandchildren are shame and be not accustomed to defecate in the river, the gutter, or the garden.

- They use latrines with their neighbors by turn.

- feeling Shame if having no toilet and have smelly defecation, If you want to charge for toilets is not expensive. No need to install expensive things or ceramic, which is important, kept clean, so it does not stink.

- families that do not have the awareness to build WC. Because of the ability in economic, they relatively have money. They do not want to make WC.

-Having wc or toilet at home is more practical and more secured do not need to go to the river, especially if you want to defecate at night or in the rain.

- their hildren build wc (toilet) because they are being used to living in the city and using the lavatory if you want to defecate.

- Defecating in in family latrines more practically, do no need to walk far from houses

- Defecating in healthier family latrines and do not pollute the environment

- Feel shame if there are guests and no latrines.

- If the houses do not have family latrines are squalid, their houses have bad odor (rotten).

"People who want to defecate (mising) in the toilets, but most people are not able to build them, because it is expensive and they do not have money to do it. Money is preferred to buy food and their children's school fee. Local people are accustomed to defecate (mising) wherever they like, especially in the river. The reasons were more practical and cleaner. Rich families' houses generally have toilets" (interview, June 2013. IS, 52, S2, Head of Health Office in Lebong regency).

\section{Reality of No Smoking in the House}

Smoking in the District Lebong has entrenched in everyday life, based on some information from several public figures and the fact reinforced by the observation is found in ordinances or customs of society provide cigarette in such a sacred event such as basen Kutei (customary deliberation), welcome the dignitaries, dispute deliberation are resolved amicably at the wedding, which is usually presented in the house. In addition to preparing cigarette as symbol, cigarettes supply or serve when entertaining (praying and eating together) when there is any event always provides cigarette in a glass or a plate to the invited guests who are attending. 
Table 4. Informal Characteristics and Social Construction Description of Smoking in the House

\begin{tabular}{|c|c|c|}
\hline No. & $\begin{array}{l}\text { Characteristics of } \\
\text { Research Subjects }\end{array}$ & Social Construction Description of Smoking in the House \\
\hline \multirow[t]{4}{*}{1.} & \multirow{4}{*}{$\begin{array}{l}\text { Housewives have 1-4 } \\
\text { children, elementary } \\
\text { to junior high school } \\
\text { level, low economic } \\
\text { class, cultural observer }\end{array}$} & $\begin{array}{l}\text { - Smoking in the house is very common, husband / father who } \\
\text { does not smoke is less masculine }\end{array}$ \\
\hline & & $\begin{array}{l}\text { - Ritual salvation /party should provide cigarette in the house or } \\
\text { consider stingy, single boys are prohibited smoking if being } \\
\text { unemployed }\end{array}$ \\
\hline & & $\begin{array}{l}\text { - There is no prohibition for men and women to smoke in public } \\
\text { places and in the home. }\end{array}$ \\
\hline & & $\begin{array}{l}\text { - For girls if smoking judged to be inappropriate, and consider } \\
\text { 'naughty', Smoking is substitute makan sirih (betel) for } \\
\text { mothers. }\end{array}$ \\
\hline
\end{tabular}

2. Housewives have 1-2 children graduated from high school education, middle and lower economic classes

3. Informants choose $2-3$ children, junior high school education level, middle and upper economic levels, religious leaders, other community leaders, cultural figures.

4. Housewives from middle to upper class, junior to senior high school levels, integrated service station cadres (kader posyandu), health department
- being tired to ban their husband's smoking, ignoring if giving advise, husband Frequently have coughing but still smoking

- Fear to ban husband's smoking, he does not want to work to earn money. Let husbands smoke, being shame to the neighbors to argue because of smoking

- Do not ban husband to smoke, because the mother also smokes, smoked Kids should be able to find his own money to buy cigarettes.

- Smoking is designated as an effort to relieve cold and to repel mosquitoes while working in rubber fields.

- Smoking physically makes stronger if having stung animals / insects venomous, Smoking is not religiously forbidden, it only should avoid, but because it is addictive, hard to quit

- Smoking among adolescents in Lebong has done since many years ago, in secret, has entrenched in Lebong, for formal occasions like weddings in place of betel should be provided smoking

- at any events such as party or other celebration, cigarettes should be provided by the host, if not available consider stingy.

- Smoking should be banned in the house, because of all the family members can be a passive smoker, Smoking can cause lung problems

- Smoking can cause various types of cancer, smoking at home gives bad examples of both in children and or other family members can be a passive smoker

- Passive smoking is more dangerous than active smokers, spend much money, cigarette prices quite expensive, only focus on enjoyable. Cost of cigarettes can be for the family's needs.

A humanist in Lebong said that "It's difficult to prohibit people in Lebong to smoke in the house. Almost all adult men and even teenagers are smokers, There are the customary ordinances should be adhered to provide cigarettes in 'bakoa iben' when there is a celebration of marriage and others have to be provided cigarettes, it's already exist in here (Lebong) If someone does not smoke is considered 
not get along"(Interview, August 2013, SJ, Senior Humanist in Lebong, 65 years old, Junior High School).

Table 5. The role of significant others SHLs of the Family in Lebong district Bengkulu province 2012

\begin{tabular}{llll}
\hline No & \multicolumn{1}{c}{ SHLs indicators } & \multicolumn{1}{c}{ Significant other } & \multicolumn{1}{c}{ Significant others } \\
\hline 1. & Childbirth & Mother & Mother, grandmother \\
2. & $\begin{array}{l}\text { Pemberian ASI } \\
\text { Eksklusif }\end{array}$ & Mother & $\begin{array}{l}\text { Mother, grand mother, sister and } \\
\text { other family members }\end{array}$ \\
3. & $\begin{array}{l}\text { Bowel habit } \\
\text { Smoking habit at home }\end{array}$ & $\begin{array}{l}\text { Father and Mother } \\
\text { Father or brothers }\end{array}$ & $\begin{array}{l}\text { Another family or neighbors } \\
\text { Fathers, mother grandparents and } \\
\text { men }\end{array}$ \\
\hline
\end{tabular}

\section{Discussion}

\section{Childbirth}

Being found three construction in selecting childbirth in Lebong (1) Choosing to be helped by piawang (traditional birth attendants), it is more liked by pregnant women because (a) the cost is cheaper, no appropriate rates, can be paid with other ways or be paid by installment (b) Feeling more comfortable because there are still family relationships, knowing well and having a lot of experience, (c) being able to massage and expel spirits or the devil (non-medical issues) (d) being able to take care of mothers and babies for longer, the mothers need three days and babies have 7-9 day care or until the baby's umbilical cord looses and (e) being fear of using midwife equipment. (2) Choosing the midwives to give birth are less preferred by mothers in Lebong, the reasons (a) despite the high costs, the important thing is morhers and infants safer (b) feeling safer and more professional, (c) more hygienic, (d) being able to check the blood tension, give injection, medication and vitaminsm, being able to immunize. (3) choosing a midwife for helping piawang and feeling safer and more comfortable, checking their pregnancy with a midwife and giving birth with a piawang (shaman). The conditions of multi choice of delivery assist is a positive side to save mothers. Based on the results of the research in Bangladesh were found that delivery complications were identified by informal health care providers and relatives, there were more than $50 \%$ never referred to skilled nursing staff $^{11}$. The results of the research in Lebong that there is an indication that the families were aware of the safety in the delivery process, although they do not forget local wisdom habits of Rejang tribes.

Childbirth with piawang (shaman) also occurs in public health centers (Puskesmas) Punngelan II in Banjarnegara, people apparently still need piawang to help childbirth, this condition is caused by their knowledge, attitude and culture ${ }^{12}$. Giving birth has more than one help, being also done by Dayak Ngaju ethnic in Kalimantan, Indonesia choosing multi cares in giving birth is a modern way (doctors or midwives), piawang and care used by the Dayak ethnic customs ${ }^{13}$. All of these findings, particularly in Lebong according to Berger, influence significant others that have stock of knowledge ${ }^{14}$ about childbirth helped by piawang, while chilbirth uses multicares is externalization process, and public adjust with health modernization, because in everyday life is objective or already established by object structures that has been given names such as piawang (shaman) since previous time.

\section{Exclusive Breastfeeding}

Exclusive breastfeeding for the babies lasts for six months without giving other foods in addition to breast milk, it is very hard to find in Lebong. There are some evident from the study in five villages in Pinang Belapis subdistrict, there is no informant giving the exclusive breastfeeding for their babies and no informant also gives testimony to know that there are a single mother in Lebong who practice exclusive breastfeeding as being recommended by the local government (Lebong Health Office). Generally mothers in Lebong give non exclusive breastfeeding because the newborn child who is at the 
age of 1-2 days crying means to feel thirsty or hungry. While waiting for the milk to come out, family habits in Lebong give babies with honey, sugar water, sweet tea or formula milk for families who can afford to buy it. Furthermore, it has construction from generations to generations that mothers in Lebong have a habit giving extra food to their babies at the age of 3-4 months consist rice flour porridge plus brown sugar (palm sugar), rice strain team, bananas, bread, fromina porridge (instant product) or whatever is as long as soft and no much spicy.

In reality, there is no evidence that breastfeeding can be replaced by water, tea or juice found if the formula milk is given to the babies over $9 \%$, in the future it may lead obesity ${ }^{15}$. Findings about $20 \%$ of mothers who practice exclusive breastfeeding for 6 months, being doubt and worrying baby have less food because babies also need to eat a lot to grow ${ }^{16}$. Another study proves if exclusive breastfeeding provide less than 6 months is estimated to contribute 1.4 million infant deaths and $10 \%$ mortality rate, so that it is recommended for mothers breastfeed exclusively to their babies until six months of age ${ }^{17}$.

The results of the studies above that mentioned above is based on social construction theory, self individual awareness and realize the realities (in the context of SHLs) are formed in accordance with the roles (needs). In the objective structure, it makes someone not just play a role but also "become" (do), because the human product social structure, in other words, giving breastfeeding to the babies, produced by human and arranged by policy makers (WHO) ${ }^{4}$. Social structure itself was created by a man through a long journey occurs in the process of 'externalization' that the public will continue to adjust to the real life ${ }^{14}$. In Lebong, exclusive breastfeeding adjustment has not been implemented, because the role of significant others still believed and followed from generations to generations. Policy makers should pay more attention to the reality of life that still has a tradition occurring in family primary socialization needs to be considered.

\section{Healthy Latrine}

In externalitation family used to defecate at any places in Lebong such as in a river, in the garden or in the gutter, only a small proportion of healthy family latrines. The condition has become a habit, especially for families who can not afford or rural families in general in Lebong ${ }^{18}$. However, when they are given adequate materials to make free latrines, families in Lebong want to make latrines do mutual cooperation and want to use the latrines ${ }^{19}$. The basics of knowledge obtained through objectivity of the subjective process (and meanings) that makes inter-subjective behavior because all human activities occur in the externalization process to form a habit that undergoes institutionalization ${ }^{14}$ and Schutz called a life world or the world of everyday life is inter-subjective world ${ }^{20}$ where people create social reality as well as constrained by social structures and culture that previously existed are created by its predecessors. Realities that surround the individuals are the knowledge. Berger and Luckmann defined that knowledge itself is "the certainty that phenomena are real and that they possess specific characteristics ${ }^{9}$.

\section{No Smoking in the House}

Smoking habit in Lebong is difficult to eliminate that has become to be entrenched because it shows masculinity if not smoking stigmatizes that he is not manly, not rich (poor people and being not able to buy cigarettes)._Another opinion expressed if no smoking feels headache, cannot concentrate to think and cannot work, reinforce the position of adult males. There is a prohibition of the parents that the children who have not been able to find the money cannot smoke. They may be permitted if they have worked and had their own money to buy cigarettes. While the reasons for women in Lebong smoke to replace muk iben (betel nut) because smoking is more practical if the betel nut is not practical (spend much time). Smoking can relieve cold and sleepy when is on duty and can repel mosquitoes while tapping rubber. This condition that causes most women in Lebong also have the habit of smoking. The reality of smokers in Lebong are very dangerous and threatening for public health, since there is an estimated one-fifth of people in the world die each year because the disease is associated with smoking, such as lung cancer substantially happened in the United States ethnic, the indigenous people of Hawaii, Olinesian, Japanese and Hispanic most $(80 \%-90 \%)$ of these cases are caused by smoking ${ }^{21}$. 
Various of the social stocks of knowledge are caused the individual would go on many diverse institutional structures, such as schools, companies, religious organizations and others, each has its own regulations which individual constructions ${ }^{14}$.

The construction is caused by stock of individual knowledge that is externalizing which gives the wrong meaning of the concept of smoking, so it has not been fully accepted by social stock of knowledge about the dangers of smoking. In fact, smokers in Lebong are considered structured and patterned reality, become custom and culture, it is entrenched and followed from generations to generations continuously.

This reality is considered as an order and pattern, usually taken for granting and non-problematic due to the pattern of interactions (typified), the reality is equally owned by others ${ }^{14}$. Through externalization, society is a product of human being, through objectivization, the community became a reality of Sui generis, unique and through internalization, human being is a product of society ${ }^{14}$.

\section{Conclusion and Recommendation}

SHLs (Sanitary and Healthy Life Style) plays rules to increase the HDI (Human Development Index). The reality of this research indicates that SHLs is controlled by the stock of knowledge in the internalization of families through primary and secondary socialization, the influence of significant others is still strong from generations to generations.

By externalizing, smoking is culture. In objectivization, situational factors such as poverty, distance, health facilities, education and habits, contribute to determining the social construction of the family to implement SHLs. There are other SHLs topics such as scalling toddlers every month, washing hands with soap, cleaning water, doing physical exercises, eating fruits and vegetables and being free from mosquito larvae, are not discussed in the context of the study of Bergerian social construction, it needs further research.

\section{Acknowledgments:}

Thanks to Prof. IB. Wirawan and Oedojo Soedirham at Doctoral Program in Social Politics Airlangga University, Surabaya Indonesia, has provided guidance in the writing of a dissertation. Prof.. Safnil, Ph.D., at University of Bengkulu Indonesia, to provide guidance in composing the International Journal.

\section{References}

Abdillah Ahsan http://muktiblog.com/pesan-hidup/bahaya-merokok-bagi-kesehatan

Banu.M, Choudhury RH Begum. K Akter. M, Nssreen HE (2014). 'The clock keeps ticking' - the role of a community-based intervention in reducing delays in seeking emergency obstetric care in rural Bangladesh: A quasi-experimental study. Journal Public Health 128 (4), 333-340.

Berger dan Luckmann (1966). The social construction of reality, a treatise in the sociology of knowledge. Middlesex.

Berger, Peter L, and Thomas Luckmann (2012). Social reading toward the reality (Treatise on the sociology of knowledge), (Translated by Hasan Basri). Jakarta.

Berger, Peter L. (2004). Pyramid of Human Sacrifice in Political Ethics and Social Change (Translated by A. Rahman Toleng). Jakarta.

Department of Health of the Republic of Indonesia (2007). Pocket book of healthy household with SHLs, health promotion center, Jakarta: MOH (Indonesia).

Haismal H, W A Coward, E Albernaz, G H Visser, J C K Wells, A Wright, et. al. (2003). Breast milk and energy intake in exclusively, predominantly, and nutrition. European Journal of Clinical Nutrition, 57, 1633-1642. 
Hamida, Diana Sofyan (2005). Maternity and Belief of Dayak Ngaju in Palangkaraya, Central Kalimantan (Dissertation) Jakarta: University of Indonesia.

Hannele, Palosuo and Ossi Rahkonen (1989). Sociology of health in finland: fighting an uphill battle? scandinavian sociological association acta sociologica, 262-263.

Health Office of Bengkulu province. (2011). Report of environmental health programs. Bengkulu (Indonesia): Health Office of Bengkulu province.

Health Office of Lebong regency. (2009). Pocket book of healthy household with SHLs, Lebong (Bengkulu): PHO Lebong.

Herlina, Muria (2010). Attitudes and behavior of family health in Bengkulu (Indonesia). Kutei Journal, 2(4), 87-95

Herlina, Muria (2009). Studies of various factors on healthy houses in Subdistrict of Embong Uram, Lebong regency, Bengkulu (Indonesia): DHO Lebong. http://www.suarasurabaya.net/v06/kelanakota/id=7d3c4f1bc283c64292003b3b7d4ee702201210 295. Accessed on 6 November 2012.

Mia Susanto (2011). Reports of The Association of Indonesian Breastfeeding Mothers (Republika, the daily news), $4 \& 16$

Ministry of Health of the Republic of Indonesia. (2010). Basic Research, National Report. Jakarta: Ministry of Health of the Republic of Indonesia.

Mulyanti, Anik (2009). Factors associated with the choice of Piawang (Shaman) as birth attendants in public health centers of Punggelan 2, Banjarnegara regency. (Undergraduate Thesis) Diponegoro University.

Poloma, M. Margaret (1979). Contemporary Sociological Theory. New York: Mac Millan.

Proverawati, Atikah dan Rahmawati Eni (2012). Sanitary and Healthy Life Style (SHLS), Yogyakarta: Nuha Medika.

Setyowati, Exsi and Rahayu Faizah Betty (2008). The relationship of health workers knowledge about exclusive breastfeeding with the ability to provide health education on exclusive breastfeeding to the prenatal mothers in Public Health Center II Kartasura, News Journal of Nursing, 1(2), 5157.

Spradley, James P. (2007). Ethnographic research method. London: TiaraWacana.

World Health Organization (WHO) maternal and infant mortality rate in Indonesia is available at : http://www.who.int/healthsystems/topics/financing/healthreport/P4PWHR 2010ShefflerFINA L.pdf 